Article

\title{
On the Acceptance of the Null That by Bilingual Catalan/Spanish L2 Learners of English
}

\author{
Mireia Llinàs-Grau ${ }^{1}$ and Aurora Bel ${ }^{2, *}$ \\ 1 Department of English and Germanic Philology, Autonomous University of Barcelona, \\ 08193 Bellaterra, Barcelona, Spain; Mireia.Llinas@uab.cat \\ 2 Department of Translation and Language Sciences, Pompeu Fabra University, 08018 Barcelona, Spain \\ * Correspondence: aurora.bel@upf.edu
}

Received: 25 February 2019; Accepted: 21 May 2019; Published: 30 May 2019

\begin{abstract}
The research presented in this article aims at providing new data on L2 learner knowledge and recognition of the null that in complement clauses. The speech of English native speakers reveals a kind of variation which implies that where that may be present or absent in clauses selected by many common verbs such as say or think there is no preference for one of the two options. In this article, judgement data of bilingual Catalan/Spanish upper-intermediate and advanced L2 learners of English are analysed bearing in mind two possible factors that, according to previous research, may influence the acceptance of this phenomenon, level of proficiency and absence versus presence of instruction. A relevant issue regarding this construction is that performing like a native does not always imply using one grammatical structure in the target language and gradually doing away with the use of another ungrammatical one; it rather implies being able to detect native speaker frequency in the use of one of the two possible options, overt that usage or the null that. Our results show that learning in this domain depends more on degree in language proficiency than in the specific instruction provided, that both choices do not pose the same difficulty and that advanced L2 learners of English can display a native-like acceptance of the null that option. The option that presents more challenges is the one where there is no L1 facilitation.
\end{abstract}

Keywords: second language acquisition; null that complementizer; overt that usage; L2 English; experimental judgement data

\section{Introduction}

The phenomenon of that-omission (or the null that) as illustrated in (1) is a characteristic property of English, and yet it is not found in the curricula of English as a foreign language (Llinàs-Grau et al. 2013; Wulff et al. 2014).

\section{(1) a. They think that Donald will do it \\ b. They think Donald will do it}

Although there is no semantic change when that is absent, there are a number of conditions that favour the null that. Absence of that is most common in contexts which involve informal speech, whereas that tends to be included in written and formal texts. Nevertheless, even if the conditions triggering that-omission hold, native speakers do not always choose a null that, which makes this phenomenon more variable. This variability in the production of null that by native speakers makes input to second language (L2) learners ambiguous since there are no clear cues that L2 learners can rely on.

In terms of language variation, the phenomenon is not found in Spanish or Catalan (the two native languages of the subjects of our experiment), as the Spanish (2) and Catalan (3) translations of (1) illustrate: 
(2) a. Piensan que Donald lo hará (Spanish)

b. * Piensan Donald lo hará "They think Donald will do it"

(3) a. Pensen que en Donald ho farà (Catalan)

b. * Pensen en Donald ho farà

"They think Donald will do it"

In Spanish and, to a lesser extent, in Catalan there are a few contexts where the complementizer can be dropped. In contrast with English, a null que is only allowed in very formal and infrequently used in contexts which involve the subjunctive, as in (4) and (5). Therefore, a complementizer deletion in the two languages is not equivalent:

(4) Deseamos tenga usted una feliz estancia (Spanish)

"We hope you have a pleasant stay."

(5) Preguem esperin a ser atesos (Catalan)

"Please wait to be attended to"

(Llinàs-Grau and Fernández-Sánchez 2013)

Although the surface construction is similar in that there is a complementizer missing in English, the constructions that allow the null that in Catalan and Spanish do not involve the same process as the one that may be responsible for the missing complementizers in English (see Llinàs-Grau and Fernández-Sánchez 2013).

As for Second Language Acquisition (SLA), learners with similar linguistic backgrounds to our participants (see Section 5) seem not to have completely acquired the process of that-omission at intermediate levels (Llinàs-Grau et al. 2013), nor at advanced levels (Llinàs-Grau and Mayenco 2016).

A question that arises in view of these facts is whether instruction can help the acquisition of the null that. In this paper we provide data that suggest that for certain tasks, more advanced learners have a near-native-like behaviour in their choices of both the null and the overt that in complement clauses. In Section 2 we briefly describe some of the factors that determine the use of overt and null that. In Section 3 we consider previous research on the acquisition of the phenomenon. In Section 4 we explain our research questions. In Section 5 we expose our experiment. The results are presented in Section 6 and discussed in Section 7. We end the article with a final conclusion in Section 8.

\section{Conditions and Constraints on the Null That Phenomenon}

There is no general consensus on what the grammatical process responsible for that-omission is. Proposals that account for the null that differ in many ways, some of which are: the nature of the complementizer that when it is absent-e.g., a null affix (Bošković and Lasnik 2003) or a null complementizer (Adger 2003; Radford 2009); the nature of that when present-e.g., a C head (Adger 2003; Radford 2009), a dummy element (Franks 2005), or a T-element (Pesetsky and Torrego 2001); the specific place of the grammar responsible for its presence or absence-e.g., the syntax (Pesetsky and Torrego 2001; Rizzi and Shlonsky 2007), the phonological component (Bošković and Lasnik 2003; Franks 2005), and the mechanism responsible for its presence or its absence-e.g., PF-affixation (Bošković and Lasnik 2003), insertion at PF (Franks 2005), T-movement (Pesetsky and Torrego 2001), or truncation (Rizzi and Shlonsky 2007). There are also proposals which make reference to a process of 'grammaticalization' of the items in 'I + think' (see Tagliamonte and Smith 2005, and references cited there), which would make the complementizer unneccesary given that the construction does not contain a complement clause.

The number of proposals to explain its usage indicates there is no consensus about how to account for this variable phenomenon. Moreover, optionality of that coexists with non-optional contexts of two types: sometimes that must be present, as in (6) and (7), and sometimes that must be absent, as in (8) and (9). 
(6) Jason whispered * (that) the phoenix had escaped.

(Adger 2003, p. 290)

(7) Billy quipped *(that) he saw a ghost.

(Franks 2005, p. 8)

(8) Who did you say $\left({ }^{*}\right.$ that) voted for Hillary?

(9) A: What do you think that Bill will say?

B: I imagine ( ${ }^{*}$ that) nothing at all.

(6) and (7) indicate that certain verbs ('manner of speaking' verbs such as whisper and quip) do not allow a null that. (8) is a that-trace effect construction, where extraction of the subject requires omission of the complementizer, and (9) is an embedded fragment answer, where a null that is also required.

Whichever grammatical account of the null that turns out to be correct, there are two essential facts: (a) it is the most common option in present day English (in all English dialects), and (b) the phenomenon is associated with a number of different factors. As Tagliamonte and Smith (2005) explain, both diachronic and synchronic data reveal that this may be a case of language change. An analysis of historical texts shows that from categorical (overt)use of that in Old English and predominance of overt that usage in Middle English, the amount of variation and the null that presence increased with time to become the most common option chosen (more than $90 \%$ of the time) in Present Day English. The fact that the phenomenon is associated with a number of factors of different kinds, such as register, adjacency or verb type is also essential.

We have already noted that verb type may be relevant in examples (6) and (7), where 'manner of saying' verbs seem to disallow the null that. Informal speech, on the contrary, tends to favour different the null that (10), while formal and written context disfavours it (11):

(10) A: Did Lucy say who's comin' to the party, Jack?

B: She said she didn't wanna tell me!

(11) It is accurate to say that concern is widespread about an alleged laxity in British immigration policies.

(Letters to the Editor, The Economist, November 2007)

The dialogue in (10) is an informal conversation among friends, where the inclusion of that would sound odd. This generalized use of null that in informal register is certified by Biber et al. (1999) who state that it is the norm in 'conversational' register. Tagliamonte and Smith (2005) also find 'overwhelmingly high' rates of the null that in spoken corpora.

The sentence in (11) is an instance of a formal written letter to the editor of a journal, an example of written formal register, which Llinàs-Grau and Fernández-Sánchez (2013) analysed and found that only less than $20 \%$ of that-complement clauses contained the null that (in 78 letters). Biber et al. (1999) consider 'academic prose' to be a context favouring overt that usage. Tagliamonte and Smith (2005) also find that there are less instances of the null that in written texts, where they discover genre differences (learned science texts have lower rates of the null that).

A different kind of constraint that seems to be at work in the use of that is adjacency. If the example in (1) is modified by including a parenthetical between the verb and the complement clause that it selects, then that must be present:

\section{(12) They think—or so they told me -*(that) Donald will do it}

Intervening material between the verb and the complement clause is considered one of the factors that make a construction 'syntactically complex' by Tagliamonte and Smith (2005) and thus may favour the overt that instead of the null that. If we consider all these issues in relation to the L2 performance of the phenomenon, a protracted development in the use of the null that variant in L2 performance is expected given the number of factors that determine the two options, together with the ambiguity of the input and the lack of transferable L1 knowledge (since neither Spanish nor Catalan have an equivalent to the null that). These individual factors are further developed in Section 4 below. In this piece of research, we specifically address the lexical verb factor. 


\section{The Null that and Second Language Acquisition}

There is not much research on the L2 knowledge and performance of the null that. The few existing studies have found that the native languages of learners influence their L2 production (Llinàs-Grau et al. 2013; Wulff et al. 2014). There may also be transfer from a subsequently learned language on the production of the null that to a previously acquired language (Llinàs-Grau and Mayenco 2016). Thus, the learner production of the phenomenon seems to be affected by positive, negative and regressive transfer. We report the few studies that have analysed the phenomenon in some detail since our research is directly related to the results found there.

In Llinàs-Grau et al. (2013), 184 essays written by bilingual Catalan-Spanish students ranging from 14 to 17 years of age were analysed in terms of the number of instances of the null that as compared to the number of overt that usage production in complement clauses. Four groups were created according to the different school or highschool classes they attended (3rd ESO 13 year olds, 4th ESO 14 year olds, 1st Batxillerat 16 year olds, 2nd Batxillerat 17 year olds). The proficiency levels in English ranged from pre-intermediate to upper-intermediate. The input they had been exposed to was reduced, as is often the case in instructed SLA settings, where teachers are not native and the L1 may be used in class. The textbooks used were also analysed and, although no explicit instruction was provided on the null that option, exercises contained both the usage of overt and non-overt that complementizers in complex sentences containing verbs like say or think.

The results showed that, although students from all 4 groups used both complement clauses with the null that and with overt complementizers, there was a strong preference for that-presence. Low percentages of the null that were attested (of the total complement clauses produced, only $29.86 \%$ contained instances of the null that). The mean number of words per essay increased as the level also increased, which could be taken as evidence of learning, but the amount of the null that instances remained below $30 \%$ even in the most advanced group. Although the study did not include a control group, native speaker behaviour in other studies indicates that that-drop reaches $90 \%$ or even higher in informal contexts such as the CHILDES corpus (Llinàs-Grau and Llinàs-Grau and Fernández-Sánchez (2012) analysed 3288 utterances of adult child-directed speech). Moreover (see Section 2) both Biber et al. (1999) and Tagliamonte and Smith (2005) observed that the use of that-omission is the preferred option in native English. Thus, despite potential differences in register, the data in Llinàs-Grau et al. (2013) suggest that learners do not perform like native speakers, and that there is a strong preference for the usage of overt complementizer production, which might be attributed, at least in part, to L1 transfer.

Llinàs-Grau and Mayenco (2016) considered regressive transfer in the production of the null that. The subjects studied were Catalan/Spanish bilingual university students with an advanced level of English (high B2, C1 or C2 according to a placement test). Participants were split into three groups: a control group, a group of students learning German, and a group of students not learning German. The objective of the study was to see if L4 German, which has the null that option, like English, could influence the production of this construction in L3 English. In other words, positive transfer of the null that option would predict more instances of the null that in the [+German] group. Using a written production task, participants were asked to continue a sentence after being shown a prompt on a screen which triggered the use of a complement clause, as in (13):

(13) "Noam is writing a novel".

Only I know this.

Only I know .... .

Participants were told to use informal, spontaneous utterances and given only $36 \mathrm{~s}$ so that they produced something quickly. The results of the experiment showed significant differences in the use of the null that between the two groups. The control group produced the null that $70.88 \%$ of the time, the [-German] group $30.65 \%$ of the time and the [+German] group $61.22 \%$ of the time. This can be attributed to positive transfer from German, suggesting that learning German enhances the production of the null that in previously acquired English. German influence on L3 English can be seen as preventing or 
diminishing the effect of negative transfer from L1 Catalan and L2 Spanish. Moreover, transfer from German can be related to the typological proximity between the two Germanic languages-German and English-and support the Typological Primacy Model of the initial stages in L3 acquisition outlined by Rothman and collaborators (Rothman and Amaro 2010; Rothman and Halloran 2013; Cabrelli Amaro and Rothman 2015; Rothman 2015, among others).

In a different study, Wulff et al. (2014) analyzed a corpus of data with the aim of determining if learners are sensitive to the many factors (see Section 2) that determine native speakers' choices in the production of the null that. Apart from direct object clauses, which are the ones we consider in our experiment, Wulff et al. (2014) study also analyzed other contexts where the null that is allowed. They compared data from two complementary sources: the International Corpus of English (native speaker production) and the International Corpus of Learner English (non-academic student essays by intermediate-advanced learners). Their findings, which are relevant to our study since they compare the production of the null that of both German and Spanish learners of English, show (1) that learners produced significantly higher proportions of overt that usage than native speakers in direct object complement clauses and (2) that Spanish learners were more conservative than German learners since German learners produce the null that more than Spanish ones. Thus, the L1 background of the learner is also revealed as a relevant factor in the production of the null that. This indicates positive and negative transfer from each of the two native languages (Spanish and German) of the L2 English learners, in accordance with the findings of the other two pieces of research summarized in this section.

To conclude this section, we can say that the few studies that have addressed the L2 knowledge of that omission have observed crosslinguistic influence although they have only analyzed the construction based on production data. None of them have assessed whether explicit instruction can be effective for this construction and result in improved participant performance. This is why we will include instruction in our design and approach the phenomenon from a different perspective, that of judgement data, in order to complement available production data as we explain in the following sections.

\section{Theoretical Considerations and Research Questions}

Up to this point we have observed that the results of previous research corroborate the expectation that acquiring the null that is a challenge for L2 learners and that it is a difficult construction to use in a native-like manner and proportion. Both intermediate and advanced learners produce low rates of the null that in production tasks and in corpus studies. The ambiguity of the input, due to the coexistence of optional and non-optional contexts of the null that, and the number of conditioning factors involved (see Section 2) make this a predictable result, especially in the light of recent L2 proposals. In the current study, we focus on optional contexts, i.e., verbs that optionally allow null that in complement that-clauses. However, the role that variation related to register or adjacency plays in the deletion of that falls outside the scope of this paper.

Regarding optionality in input, Slabakova $(2013,2016)$ considers there to be linguistic aspects that are harder to learn than others because of the architecture of language itself. Core syntactic properties do not vary among languages, but functional morphology does, and this is what the language learner has to learn. Moreover, there are language-internal facts that make certain linguistic differences between languages more difficult to acquire than others. One of the situations in which a construction can be harder to acquire by a L2 learner is when "parameter values are not fixed in overt functional morphology but are signalled by various (lexical, word order, etc.) means or are left for the discourse to supply" (Slabakova 2016, p. 46). In other words, when optionality is at stake, input becomes ambiguous. The case of the null that could be one of these situations since there is no clear functional morphology associated to the phenomenon, it is strictly related to lexical items (that, que) and a number of different factors external to the grammar condition its occurrence (see Section 2). In addition, the overuse of that evidenced in previous literature is not ungrammatical in English, so if Catalan/Spanish bilingual learners choose their L1 option, that is, overt usage of that, the result is grammatically in 
English. In the case at hand, the learner's task is to infer frequency identification from input rather than to solve a strictly grammatical problem.

Given the difficulty in the acquisition of patterns and frequency of use of null that observed in previous research and predicted by recent SLA proposals, a possibility to explore is whether null that can be enhanced by instruction. The effectiveness of instruction is an issue of debate but it is generally assumed that it can help the L2 acquisition process (Norris and Ortega 2000; Spada and Tomita 2010). Moreover, research has revealed that noticing a linguistic form is necessary to acquire it (Leow 2007; Schmidt 1990, 1995). One way in which instruction can help students notice a form is by referring to it explicitly. Explicit instruction seems to be beneficial for the acquisition of a second language (Norris and Ortega 2000) although this is an unsettled issue since results do not reveal benefits for all linguistic forms and constructions alike (Ellis 2002; Fernandez 2008). A relevant concern is whether the linguistic item to be learned is salient and frequent in the input. For some researchers explicit reference to linguistic form may be necessary to learn items that are nonsalient and less frequent (Nassaji and Fotos 2011; Spada and Tomita 2010). The type of instruction known as focus on forms (Long 1996), where students are made aware of specific linguistic forms ranges from more implicit tasks, for example consciousness-raising tasks, where students are guided into their own discovery of specific grammatical rules and patterns (Ellis 2003; Nassaji and Fotos 2011, Bosque and Gallego 2016) to more explicit ones, such as explicit instruction, where the aim of the activity is to overtly point out to the students the properties of a specific construction and where the activity is often not accompanied by any reference to context (Andringa et al. 2011; Macaro and Masterman 2006). The positive, beneficial effects of explicit instruction have been related to the fact that this is a straightforward way of making learners notice those structures which are directly mentioned and identified in the input they get (Scheffler and Cinciała 2010).

As explained in Section 3, previous research on the L2 performance of the null that analysed intermediate and advanced learners' production. In the present analysis we want to ascertain whether learners from higher level learners whose L1 does not have the null that are able to identify optionality of the two variants (the null and the overt that) in English that complement clauses and whether explicit instruction can help improve the performance of students. With these observations in mind, we ask the following research questions:

RQ1: Does explicit form-focused instruction help L2 learners converge with native speakers on the null that/overt that usage production? Can learners, particularly those at advanced levels benefit from specific training?

RQ2: To what extent does the level of proficiency affect English L2 learners' sensitivity specifically to the null that, the option which has been shown to be the most difficult for learners?

As previously mentioned, the null/overt that usage is an optional phenomenon, which seems to be harder to learn than obligatory phenomena, given that it offers unclear and ambiguous cues to the learner. In this context, we hypothesize that (a) instruction may facilitate L2 performance (Norris and Ortega 2000; Spada and Tomita 2010), and (b) more advanced learners (as opposed to intermediate learners) will display a behaviour closer to native speakers, particularly those that receive specific instruction (i.e., after intervention).

As explained in the previous section, the few proposals that have examined this phenomenon, have focused exclusively on production and corpus data; our present study, for the first time to the best of our knowledge, focuses on acceptability judgement/comprehension data. Our hypothesis regarding the selected task is that learners may, for different reasons, not access one of the two possible options (the overt usage of that and the null that) to the same extent than native speakers when engaged in language production but are able to recognize and accept both options in experimental tasks involving judgements. We thus predict higher levels of the null that acceptance than the null that production. This is an additional research question, although not explicitly formulated, given that our design 
does not include a production task. Nevertheless, our results can be indirectly compared to studies examining production data from analogous learners.

\section{Methodology}

\subsection{Participants}

A pool of 86 university L2 English students (age range from 20-22) and 11 English native speakers participated in the study. Four groups were formed: one control group of native speakers and three experimental groups classified according to the level of proficiency and 'treatment'. The levels are as follows: two advanced groups $(\mathrm{N}=34$ Advanced No-instruction group; $\mathrm{N}=25$ Advanced With-instruction group) and one Upper-intermediate (No-instruction) group $(\mathrm{N}=26)$. According to the CEFR (Common European Framework of Reference for Languages), the language levels correspond to Proficient Users (C1-Advanced) and Independent Users (B1-Intermediate and B2-Upper-intermediate), respectively. Regarding instruction, one of the two advanced groups received instruction (i.e., explicit instruction on the null that) whereas the other did not receive instruction (for the details and characteristics of the instruction, see Section 5.3).

The participants were recruited from a Catalan University and were born and raised in Catalonia, and are balanced bilingual Catalan/Spanish speakers, according to a background questionnaire administered at the time of the survey. To assess English proficiency, the learners completed a placement test (LIFE placement tests, National Geographic/Cengage learning), and answered a self-assessment questionnaire of English language skills. The relationship between the two measurements reached a satisfactory congruency. The results from the placement test significantly correlated with overall self-ratings $(r(86)=0.483 ; p=0.01)$. In addition, scores were significantly higher in the advanced groups than in the upper-intermediate group on the placement test $(t(82)=-5.060 ; p=0.001)$ and no differences were found between the two advanced groups $(t(57)=1.171 ; p=0.247)$. The members of the control group are adult native speakers that come from different English backgrounds.

All subjects gave their informed consent for inclusion before they participated in the study. The protocol was approved by the Institutional Committee for Ethical Review of Projects (CIREP-UPF) (Reference code 0032).

\subsection{Task}

To analyse the knowledge of the null that, an untimed acceptability judgment task was designed. Two conditions were tested: an overt that condition and a null that condition. A total of 24 experimental items (12 per condition) and 24 fillers were included in the test; all items were randomized. Participants were requested to rate the acceptability of each sentence stimulus on a four-value Likert scale (rates from 1 to 4,1 being the least preferred option in the acceptability task). For the sake of homogeneity, only four verbs introducing direct object that-clauses were used (say, think, hope and tell) (3 tokens for verb in each condition). According to Tagliamonte and Smith (2005) and Durham (2011) these are the verbs more likely to be used with a null complementizer. The fillers consisted of sentences containing relative clauses (12 subject and 12 object relative clauses), with an overt that and an (un)grammatical null that. Examples for each experimental condition are provided in (14) and (15) below:

(14) Null that condition

a. Your father said you have to finish your homework.

b. The students hope the exam will be easy.

(15) Overt that condition

a. Andrew said that the book was very interesting.

b. She hopes that Steven can get the job. 


\subsection{Instruction}

In order to test the possible beneficial effects of form-focused instruction, one of the two advanced groups was provided with specific information about the that-omission construction with the aim of making participants aware of the properties of the structure. Different techniques were used in the instruction period, which was provided in two class sessions and lasted a total of three hours. Instruction started with a brief description of the construction, that is, with the use of explicit instruction, where the objective was to draw the students' attention to the fact that English can either include or not include an initial that complementizer in finite declarative embedded clauses. We used examples and metalinguistic terminology since this was provided in the context of an English Syntax course, which incorporates tree and bracket analysis of constructions using terminology such as 'head of phrase' and 'empty element'. In the description of the construction we included adjacency, as a factor that apparently disfavours that-omission. The next step was to compare and contrast the construction with the equivalent structures in the students' native languages, Catalan and Spanish. In order to do this we used minimal pairs including a grammatical English sentence and an ungrammatical Catalan or Spanish sentence. Participants were asked to consider the differences and come up with the contrasting syntactic behaviour of the finite, declarative complementizers in the two languages. A consideration of how the English sentences would be best translated into their native languages was also included, as well as different texts containing the null and the overt that, including a variety of pragmatic contexts and registers that favour each of the two options. These can be regarded as consciousness-raising tasks since students were allowed to discover the contrasting patterns on their own. Next, students were asked to draw syntactic trees of clauses where the complementizers had been omitted with the aim of making them aware of the fact that embedded clauses have an equivalent syntactic structure (they are Complementizer Phrases, CPs) whether the complementizer is overt or null. This last part of the treatment sessions was theoretically-oriented explicit instruction. The intervention was implemented seven and two days before the experiment.

\section{Results}

We begin by reporting descriptive statistics regarding our main question on the acceptability performance of null and overt that usage, so we consider each condition separately (see Table 1).

Table 1. Descriptive statistics of acceptability judgments in each condition (by group).

\begin{tabular}{ccc}
\hline & Null That & Overt That \\
\hline Group & Mean/SD & Mean/SD \\
Upper-Intermediate No-instruction & $3.04 / 0.50$ & $3.54 / 0.33$ \\
Advanced No-instruction & $3.33 / 0.49$ & $3.65 / 0.34$ \\
Advanced With-instruction & $3.43 / 0.34$ & $3.76 / 0.22$ \\
Native & $3.74 / 0.25$ & $3.93 / 0.08$ \\
\hline
\end{tabular}

From the descriptive results in Table 1, high acceptability rates seem to be common to all groups in both conditions (the highest score is 4). It is important to highlight that all groups prefer the expression of that to its omission, regardless of having received specific instruction or not. Separate paired-samples $t$-tests, one for each group, were conducted on the null that and overt that scores and the results yielded significant differences in every group (UI: $t(26)=-4.083, p=0.001$; A/No-instruction: $t(43)=-3.789$, $p=0.001$; A/With-instruction: $t(14)=-2.914, p=0.011 ; \mathrm{N}: t(8)=-2.312, p=0.05)$. This confirms that, in fact, that use was generally judged as more acceptable than that omission. The four participanting groups were alike in this regard.

To determine whether the different groups have in fact different mean ratings, a one-way ANOVA was performed on each condition with Group as the between-subject factor. In the null that condition, the most difficult condition according to the significant lower results attested as compared to those of the overt that condition, a Group effect was found to be significant $(F(3,91)=6.058 ; p=0.001)$. Post hoc 
Bonferroni tests gave near-significant differences between Upper-intermediate and advanced learners both No-instruction ( $p=0.058)$ and With-instruction $(p=0.067)$ groups, and clear significant differences between Upper-intermediate learners and native speakers $(p=0.001)$. In contrast, non-significant differences were attested between the two advanced groups and this can be interpreted as a lack of effect of intervention (or as a failure to detect such effect under the instructional conditions performed). Overall, these findings can be given the interpretation that differences depend more on language proficiency than on the specific instruction received since advanced learners (with and without instruction), but not upper-intermediate learners, perform similarly to native speakers.

In the overt that condition a Group effect was also revealed $(F(3,91)=4.420 ; p=0.008)$. A post hoc Bonferroni test yielded differences only between upper-intermediate learners and native speakers $(p=0.008)$. This result indicates that the overt that option is easier than the null that option: intermediate and advanced learners perform similarly accepting sentences with overt that whereas only advanced learners reached native-like performance in the domain of that omission. In other words, it is only the null that that appears to follow a protracted process of development. Figure 1 graphically shows the trends attested for both the null and the overt that conditions.

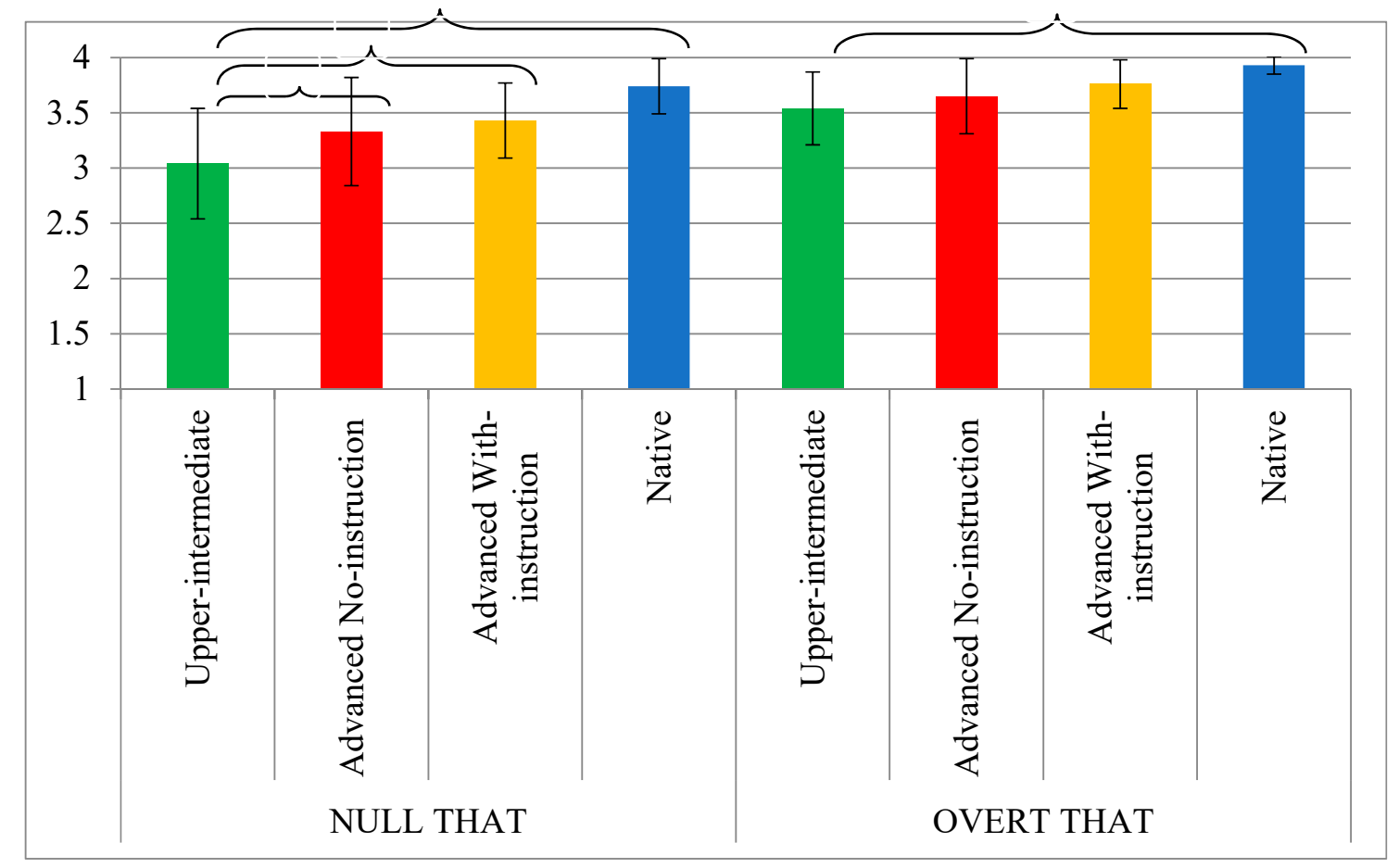

Figure 1. Acceptability rates by group and condition.

In addition to the general analyses reported, specific analyses concerning verb type were conducted. Verb type data were analyzed by a one-way ANOVA for each verb with Group as the between-subject factor. Differences were attested for the four verbs in the null that condition: 'think' $(F(3,91)=7.513$; $p=0.000)$, 'say' $(F(3,91)=4.165 ; p=0.008)$, 'hope' $(F(3,91)=3.514 ; p=0.018)$, and' tell' $(F(3,91)=5.026$; $p=0.003)$. Post hoc differences between native speakers and upper-intermediate learners were attested with all verbs. Differences between native speakers and the advanced group without instruction were only noted with the verb 'hope'. Fewer differences were attested in the overt that condition (only with the verb 'tell' $F(3,91)=4.860 ; p=0.004$, so that upper-intermediate learners were different from native speakers, $p=0.013$ ), which seems to indicate, as previously stated, that the use of that is more easily accepted than its omission (see Figures 2 and 3). Briefly, there is no significant difference in outcome with regard to any of the four verbs used, but this was expected, as we chose a homogeneous sample of verbs regarding that omission frequency. 


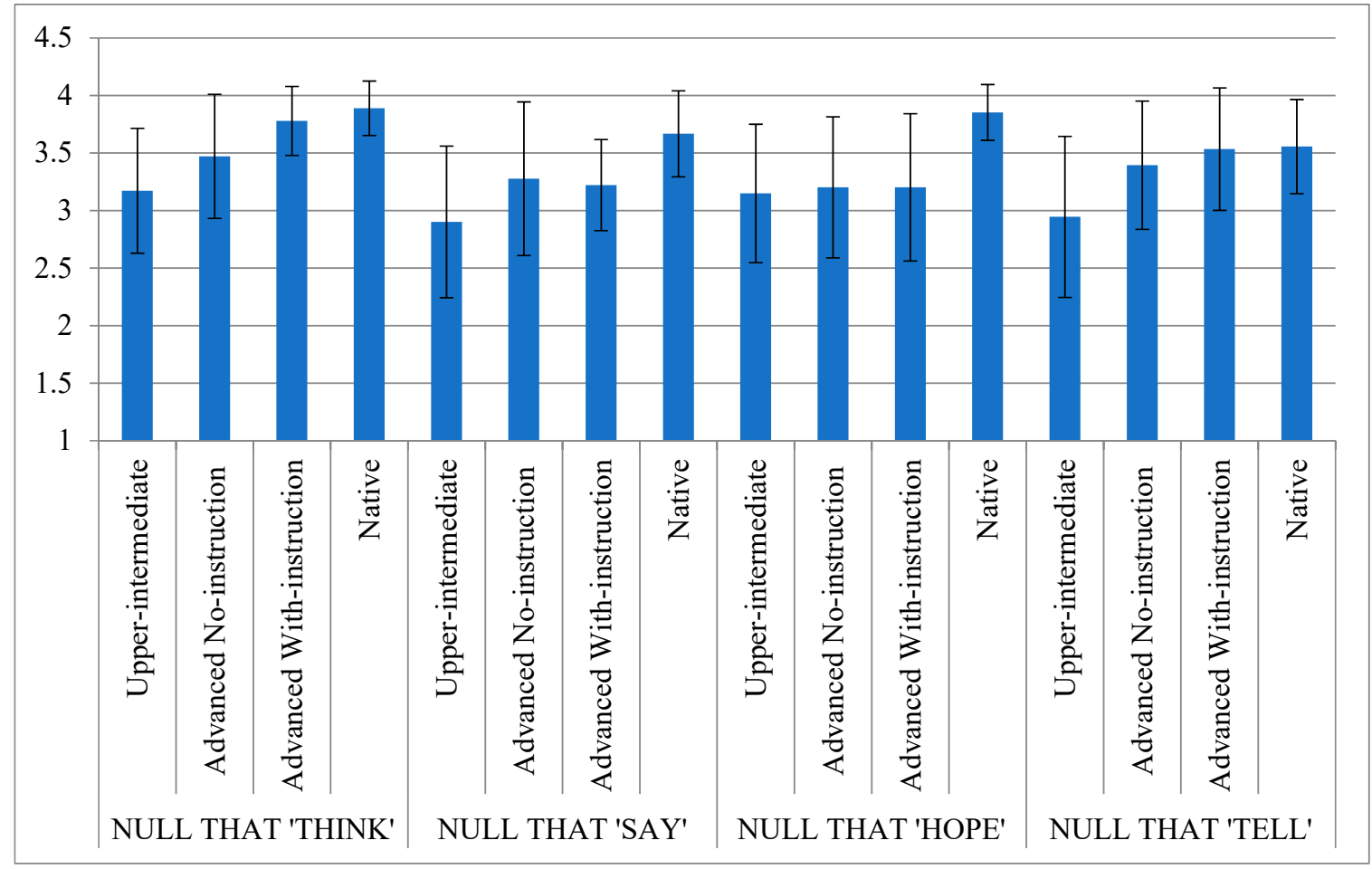

Figure 2. Acceptability rates by group and verb. Null that condition.

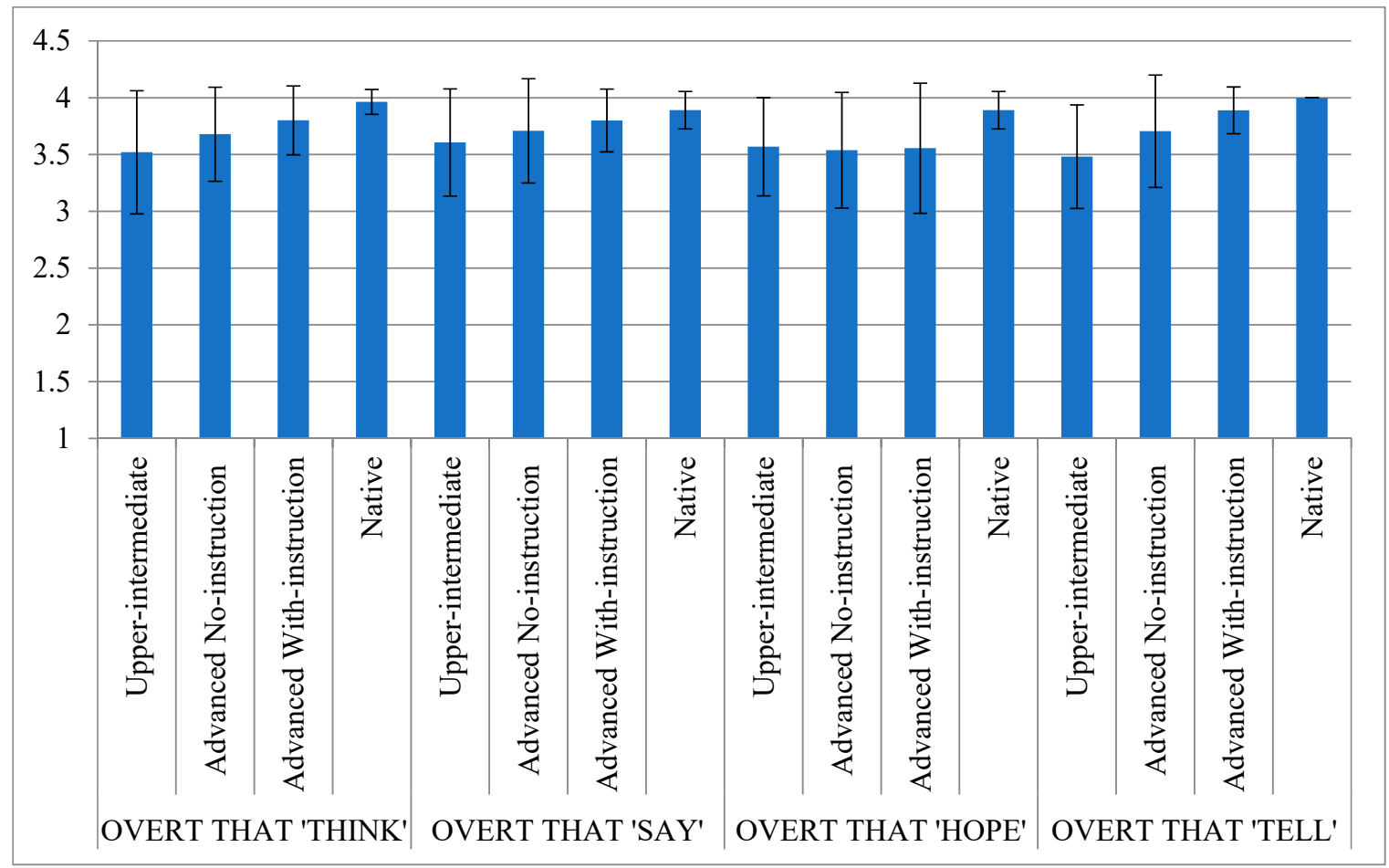

Figure 3. Acceptability rates by group and verb. Overt that condition.

\section{Discussion}

The first research question that guided our study wanted to determine whether specific instruction might enhance that variation usage and recognition in L2 English. The results of the acceptability judgment task showed no apparent effect among the L2 instructed group as their performance was similar to that of the L2 non-instructed group of the same level of proficiency. This is true both for 
the null and the overt that conditions in which non-significant differences were found between both groups. However, the most interesting finding is the one related to that deletion given that, in this case, there is no equivalent option in the L1 of our participants so that they are not influenced by eventual positive transfer, which is by contrast possible for that expression/realization. This means that the learning task facing each option is somewhat different.

Regarding the role of instruction, we found that explicit instruction did not lead to an increase in the acceptance of the null that. We hypothesized that instruction could have a positive effect on this phenomenon in line with previous research (see Section 4) yet in this study such beneficial effects are not found. The instruction we provided to our participants aimed at making them notice a construction that is not salient in the input since the omission of the complementizer is not a clearly noticeable phenomenon nor one which is easily detectable in speech. What becomes evident is that the instruction provided may have been too short or limited (Ellis 2002) and that in order for learners to behave in a native-like manner they may need more time. Participants had explicit knowledge of the construction, since they came up with the tree analysis containing a null head of the embedded $\mathrm{CP}$ and were able to express the contrasting properties of the finite complementizer in English and their native languages. They however, had not converted this explicit knowledge into implicit knowledge leading to native-like acceptance of the null complementizer. This can be related to DeKeyser (2007)'s Skill Acquisition Theory which assumes that declarative knowledge of a linguistic form of an L2 becomes procedural through practice. The lack of practice after the instruction sessions may have been an obstacle to a better performance in the task. The results we obtained in relation to the second factor tested in this experiment (i.e., level of proficiency) seem to indicate that this may be partially true. The more classes in English the advanced learners have received can help to provide the necessary cues and practice to accept the null that like native speakers. Moreover, the way in which form-meaning integration can be obtained in second language acquisition also depends on the degree of explicitness of the L2 instruction (see Section 4). In the present study, the planned instruction was explicit so that, according to some studies (Long and Doughty 2009), it should result in short-term benefits, but it is not the case here. We can also conjecture that another reason for the lack of effect of training could be that instruction was administered too late in L2 development. In spite of this, we discarded introducing instruction at lower levels of language proficiency because research suggests that the development of grammar follows a natural order (Klapper and Rees 2003; Macaro and Masterman 2006) so that instruction may be helpful if provided when learners are developmentally prepared (Ellis 1989; Pienemann 1998). Moreover, this construction is not part of the typical syllabus and learning objectives of current intermediate levels. Nevertheless, given the significant differences between the upper-intermediate and the advanced learners further research should address the role of implicit instruction on the acquisition of the that-deletion phenomenon at earlier stages of L2 language acquisition.

The second research question asked whether null that usage is influenced by proficiency level in L2 English and to what extent it is similar to that of the native group. In contrast with the non-significant role played by instruction, our results showed that L2 language level enhanced performance and sensitivity to that interchangeability in the target language. On the whole, the more advanced students displayed a more native-like understanding of null and overt that distribution. On the other hand, upper-intermediate learners did not reach nativelikeness either in the null that or in the overt that usage (despite the fact that the overt realization of the complementizer is a grammatical option also in their L1). Hence, an asymmetry was found between the two external individual factors addressed in the current study (i.e., instruction and level of proficiency) with regard to how they contribute to the mastery of optional null that in L2 English. Our results showed that those participants with a higher proficiency level (with and without instruction) accepted the null that almost like native speakers in contrast to lower proficiency level students. This could be signalling that there is effective learning, that advanced students have overcome possible L1 transfer observed in other studies (see Section 3) becoming more and more sensitive to the constraints that govern the use of the that-construction. In addition, our results suggest that proficiency weighs more than intervention, particularly in our 
case where instruction was syntax-oriented and time-limited. As mentioned above, higher proficiency levels imply more hours of input of the language and more opportunities of coming across the null that, both in classroom contexts and in activities that may incorporate real language use and a wider variety of language registers and texts, like novels or films. Precisely one of the genres mentioned by Tagliamonte and Smith (2005) as favouring the null that is fiction. What this could also be indicating is that once an advanced level is reached, students are aware of the optionality of the embedded that complementizer and accept the null that almost as native speakers. Our study suggests that when this level is reached, explicit form-focused instruction ceases to be effective.

Several other issues raised by the current findings merit further discussion. First, it seems interesting to compare production and judgement data even more bearing in mind that the learners we compare share origin and profile with those of the studies presented in Section 3. From the production data summarized in that section, the amount of null thats among learners was quite low (29.86\% in Llinàs-Grau et al. 2013, and 30.65\% Llinàs-Grau and Puig-Mayenco 2016; native proportion was 70.88\%). In contrast to these low percentages, the results of our acceptability task show that the mean acceptance of the null that by advanced students (both with and without instruction) is close to native acceptance. This comparison between tasks reveals the existence of asymmetry between production and comprehension data, as predicted when considering the type of task used in the current experiment (Section 4). The lack of parallelism between tasks may be due to the fact that there is a difference between incorporating a specific piece of linguistic knowledge-in this case, the properties of that-constructions-and producing the construction in a native-like fashion (Hendriks and Koster 2010; Hendriks 2014). Moreover, the larger proportion of the null that acceptance in our judgement data, as compared to the presence of the null that in (semi)spontaneous production data and in corpora found in previous research, seems to indicate that one of the linguistic factors that favours the null that (i.e., register) may not be so relevant. As pointed out in Section 2, that omission is associated with informality in style, in contrast with that retention, which is linked to formality and objectivity. The data analysed in this study are presented in written form, which is related to formal register, and yet our findings reveal a relatively high degree of acceptance of the null that, higher than the production results analysed in previous research. In any case, given that features like informality, emotivity or familiarity are more closely related with spoken modalities and registers, it would be important to conduct research and collect data from oral sources to ascertain whether register features can explain L2 that omission/retention behaviour.

A second interesting issue that emerges from the data reported here is an overall preference in all groups of that expression over that omission, which is in line with the general findings of L2 production and regardless of differences in the learners' L1 (see Wulff et al. 2014). In fact, as depicted in Figure 1, there is a clear progression across levels in the null-that option, that is the acceptance of the null that increases as the level of proficiency increases, whereas native-likeness is reached earlier in the overt-that option (only significant differences between intermediate learners and native speakers were attested). Moreover, the fact that learners prefer overt that coincides with Wulff et al. (2014) results, which is relevant because their study focuses on production data-more specifically, on written learner corpus data-and the one presented here is an acceptability judgement task. So what we observe with regards to overt that is that results are concomitant regardless of task type. In relation to this general pattern attested both in production and recognition (i.e., that use seems easier than the null that) following Kroll and Dussias (2013), Wulff et al. (2014) suggest that it is cognitive load in bilinguals (L2 learners in our case) that makes speakers (over)produce—or (over)accept—-the complementizer. In this case, the overextension of that in complement constructions does not entail ungrammaticality nor does it imply pragmatic infelicity, but differences in frequency use between learners and native speakers. To some extent, this is not far from Tsimpli (2011) learner's default proposal, according to which taxed processing resources may lead bilinguals to rely on an unmarked form, which in the present case would be that retention. Thus it can be suggested that the attested preference for overt that usage originates, not directly or exclusively from crosslinguistic influence of L1 options, but from cognitive linguistic strategies in an attempt to overcome the limitations imposed by processing load. 
This possibility remains speculative at this stage and needs further research and proper processing data collection.

We would like to suggest, additionally, that particularly our L2 advanced learners have acquired the grammatical knowledge and representation underlying the null and the overt that in L2 English since they are able to recognize both options similarly to native speakers (see results in Figure 1). In the case of the structure corresponding to the null that, which learners cannot inherit from their L1s (Catalan and Spanish), L2 advanced learners have mapped a new and different structure, process or item (whichever the specific syntactic analysis turns out to be correct; see Section 2), that is English-specific. Nevertheless, L2 advanced learners prefer to use the null that in their ((semi-)spontaneous) production less frequently than native speakers (as pointed out by previous studies regarding L2 production of the null that complementizer by learners of the same linguistic profile; see Section 3). Since it is known that production and comprehension (or recognition) of a given linguistic construction do not mirror each other, our goal was to identify the existence of incongruity between complementizer production (as previously attested) and acceptance rates. This divergence could be captured through an acceptability judgement test, as the one used here. After having acquired the new representation, learners still need to realize, from input exposure exploiting positive evidence, to what degree English L1 speakers use the null counterpart of the that complementizer, that is, its frequency of use. It is only by incorporating this kind of (pragmatic) knowledge that the learners' behaviour in this respect will mirror that of native speakers. This also leads us to suggest that instructed L2 learners are subject to input limitations such as quantity (i.e., frequency) and register variety (Slabakova 2016), which are relevant for the choice of the null that versus the overt that.

Finally, there is still an issue that needs some attention. Beyond figuring out what properties govern that expression in English, learners also need to be involved in lexical learning: in other words, learners must acquire the individual lexical verbal items that allow optional that-omission in complement constructions and this knowledge must also be extracted from input experience. In this regard, according to our data the verb hope is the only verb where differences between learners and native speakers are attested in the null that condition. This can be related to frequency of use. In fact, according to corpus-based investigations, as reported in Wulff et al. (2014) or Tagliamonte and Smith (2005), verbs such as tell, or hope, are less common and less frequent verbs taking that-clause complements than, for instance, think, say or know. From these findings, we can identify some degree of verb-item sensitivity among learners, who have learned the 'property' that defines the null that, but not fully the extent to which this property is applied. They have also learned to which lexical items this property is associated with but, of course, more lexical learning and practice is needed and this could possibly be better achieved in study abroad contexts.

\section{Conclusions}

To conclude, the predicted difficulty in the L2 performance of the that-omission phenomenon-given the multiplicity of cues that learners must face (syntax, lexicon, context, prosody) and the variable input they receive-is not corroborated by our results.

In contrast with previous studies that tested production, the data presented here reveal that our participants seem to have incorporated the key properties that regulate the that-omission phenomenon in their L2 grammars and that they recognise both options-the null and the overt that - when asked to judge acceptance. Nevertheless, they prefer the option that superficially coincides with their (only and obligatory) L1 option (i.e., that expression), which seems to act as a facilitative cue that is incorporated in the L2 system. This interference from the L1 system is more evident when optionality is at stake, as is the case here.

We could also infer that the potential L1 transfer observed in previous research seems to have been overcome by the input and the experience with English that our participants have received in university classes, despite the fact that there is no focus on (this) form. This is what can explain differences and development in the null that knowledge and use between the two proficiency levels 
envisaged in the current piece of research. Explicit instruction which focuses on form, at least the specific treatment in this experiment and at the advanced level, plays no substantial role. It remains open to further research to check whether another kind of instruction would lead to relatively more native-likeness in this specific linguistic domain and also whether instruction may be effective at lower levels of proficiency.

Author Contributions: M.L.-G. and A.B. conceptualized the study and designed the experiments, M.L.-G. supervised the experiments, A.B. analyzed the data and M.L.-G. and A.B. interpreted the data and wrote the paper.

Funding: This research was supported by a grant from the National Plan of Scientific and Technical Innovation Investigation (grant FFI2016-75082-P, Ministry of Economy and Competitiveness, Spain).

Acknowledgments: We are very grateful to the students that agreed to be our participants.

Conflicts of Interest: The authors declare no conflict of interest.

\section{References}

Adger, David. 2003. Core Syntax. A Minimalist Approach. Oxford: Oxford University Press.

Andringa, Sible, Kees de Glopper, and Hilde Hacquebord. 2011. Effect of explicit and implicit instruction on free written response task performance. Language Learning 61: 868-903. [CrossRef]

Biber, Douglas, Stig Johanson, Geoffrey Leech, Susan Conrad, and Edward Finegan. 1999. Longman Grammar of Spoken and Written English. Harlow: Pearson Education Limited.

Bošković, Zeljko, and Howard Lasnik. 2003. On the distribution of null complementizers. Linguistic Inquiry 34: 527-46. [CrossRef]

Bosque, Ignacio, and Angel Gallego. 2016. La aplicación de la gramática en el aula. Recursos didácticos clásicos y modernos para la enseñanza de la gramática. Revista de Lingüística Teórica y Aplicada 54: 63-83. [CrossRef]

Cabrelli Amaro, Jennifer, and Jason Rothman. 2015. The relationship between L3 transfer and structural similarity across development: Raising across an experiencer in Brazilian Portuguese. In Transfer Effects in Multilingual Language Development. Edited by Hagen Peukert. Amsterdam: John Benjamins, pp. 21-52.

DeKeyser, Robert. 2007. Skill acquisition theory. In Theories in Second Language Acquisition: An Introduction. Edited by Bill Van Patten and Jessica Williams. Mahwah: Lawrence Erlbaum Associates, pp. 97-113.

Durham, Mercedes. 2011. I think (that) something's missing: Complementizer deletion in nonnative e-mails. Studies in Second Language Learning and Teaching 1: 421-45. [CrossRef]

Ellis, Rod. 1989. Are classroom and naturalistic acquisition the same? A study of the classroom acquisition of German word order rules. Studies in Second Language Acquisition 11: 305-28. [CrossRef]

Ellis, Rod. 2002. Does form-focused instruction affect the acquisition of implicit knowledge? Studies in Second Language Acquisition 24: 223-36. [CrossRef]

Ellis, Rod. 2003. Task-Based Language Learning and Teaching. Oxford: Oxford University Press.

Fernandez, Claudia. 2008. Reexamining the role of explicit information inprocessing instruction. Studies in Second Language Acquisition 30: 277-305. [CrossRef]

Franks, Steven. 2005. What Is That? Indiana University Working Papers in Linguistics. Bloomington, IN, USA: Indiana University, vol. 5, pp. 33-62.

Hendriks, Petra. 2014. Asymmetries between Language Production and Comprehension. Studies in Theoretical Psycholinguistics 42. Dordrecht: Springer.

Hendriks, Petra, and Charlotte Koster, eds. 2010. Lingua. Special Issue on Asymmetries in Language Acquisition 120: 1887-97.

Klapper, John, and Jonathan Rees. 2003. Reviewing the case for explicit grammar instruction in the university foreign language learning context. Language Teaching Research 7: 285-314. [CrossRef]

Kroll, Judith F., and Paola E. Dussias. 2013. The comprehension of words and sentences in two languages. In The Handbook of Bilingualism and Multilingualism. Edited by Tej Bhatia and William Ritchie. Malden: Wiley-Blackwell Publishers, pp. 216-43.

Leow, Ronald. 2007. Input and the L2 classroom: An attentional perspective on receptive practice. In Practice in a Second Language: Perspectives from Applied Linguistics and Cognitive Psychology. Edited by Robert DeKeyser. Cambridge: Cambridge University Press, pp. 21-50. 
Llinàs-Grau, Mireia, and Javier Fernández-Sánchez. 2012. On the syntax and the pragmatics of 'optional' that. In At a Time of Crisis: English and American Studies in Spain. Edited by Sara Martin-Alegre. Barcelona: AEDEAN e-books, pp. 360-67.

Llinàs-Grau, Mireia, and Javier Fernández-Sánchez. 2013. Reflexiones en torno a la supresión del complementante en inglés, español y catalán. Revista de la Sociedad Española de Lingüística 43: 55-88.

Llinàs-Grau, Mireia, and Eloi Puig Mayenco. 2016. Regressive Transfer from L4 German to L3 English: The Case of that-deletion. In English on the Move. Glancing Backwards to Build a Future in English Studies. Edited by Aitor Ibarrola-Armendariz and Jon Ortiz de Urbina Arruabarrena. Bilbao: Universidad de Deusto, pp. 281-87.

Llinàs-Grau, Mireia, Elisabet Pladevall, and Montserrat Capdevila. 2013. On that-omission and its absence in the written production of bilingual Spanish/Catalan L2-learners of English. Atlantis, Journal of the Spanish Association of Anglo-American Studies 35: 35-49.

Long, Michael H. 1996. The role of the linguistic environment in second language acquistion. In Handbook of Second Language Acquisition. Edited by William Ritchie and Tej Bhatia. San Diego: Academic Press, pp. 413-68.

Long, Michael H., and Catherine J. Doughty, eds. 2009. Handbook of Second and Foreign Language Teaching. Malden: Wiley-Blackwell.

Macaro, Ernesto, and Liz Masterman. 2006. Does intensive explicit grammar instruction make all the difference? Language Teaching Research 10: 297-327. [CrossRef]

Nassaji, Hossein, and Sandra S. Fotos. 2011. Teaching Grammar in Second Language Classrooms: Integrating Form-Focused Instruction in Communicative Contexts. New York: Routledge.

Norris, John M., and Lourdes Ortega. 2000. Effectiveness of L2 instruction: A research synthesis and quantitative meta-analysis. Language Learning 50: 417-528. [CrossRef]

Pesetsky, David, and Esther Torrego. 2001. T-to-C movement: Causes and consequences. In Ken Hale: A Life in Language. Edited by Michael Kenstowicz. Cambridge: MIT Press, pp. 355-426.

Pienemann, Manfred. 1998. Language Processing and Second Language Development. Processability Theory. Amsterdam: John Benjamins.

Radford, Andrew. 2009. Analysing English Sentences. A Minimalist Approach. Cambridge: Cambridge University Press.

Rizzi, Luigi, and Ur Shlonsky. 2007. Strategies of subject extraction. In Interfaces + Recursion = Language? Chomsky's Minimalism and the View from Syntax-Semantics. Edited by Hans Martin Gartner and Uli Sauerland. Berlin: Mouton de Gruyter, pp. 115-60.

Rothman, Jason. 2015. Linguistic and cognitive motivations for the Typological Primacy Model (TPM) of third language (L3) transfer: Timing of acquisition and proficiency considered. Bilingualism: Language and Cognition 18: 179-90. [CrossRef]

Rothman, Jason, and Jennifer Cabrelli Amaro. 2010. What variables condition syntactic transfer?: A look at the L3 initial state. Second Language Research 26: 189-218. [CrossRef]

Rothman, Jason, and Becky Halloran. 2013. Formal approaches to L3/Ln acquistion: A focus on morphosyntactic tranfer in adult multilingualism. Annual Review of Applied Linguistics 33: 51-67. [CrossRef]

Scheffler, Paweł, and Marcin Cinciała. 2010. Explicit grammar rules and L2 acquisition. ELT Journal 65: 13-23. [CrossRef]

Schmidt, Richard. 1990. The role of consciousness in second language learning. Applied Linguistics 11: 129-58. [CrossRef]

Schmidt, Richard. 1995. Attention and Awareness in Foreign Language Learning. Honolulu: University of Hawaii Press.

Slabakova, Roumyana. 2013. What is easy and what is hard in second language acquisition: A generative perspective. In Contemporary Approaches to Second Language Acquisition. Edited by Maria Pilar García Mayo, Maria Juncal Gutierrez-Mangado and Maria Martínez Adrián. Amsterdam: John Benjamins, pp. 5-28.

Slabakova, Roumyana. 2016. Second Language Acquisition. Oxford: Oxford University Press.

Spada, Nina, and Yasuyo Tomita. 2010. Interactions between type of instruction and type of language feature: A meta-analysis. Language Learning 60: 263-308. [CrossRef]

Tagliamonte, Sali, and Jennifer Smith. 2005. No momentary fancy! The zero 'complementizer' in English dialects. English Language and Linguistics 9: 289-309. [CrossRef] 
Tsimpli, Ianthi Maria. 2011. External interfaces and the notion of "default". Linguistic Approaches to Bilingualism 1: 101-3. [CrossRef]

Wulff, Stefanie, Nicholas Lester, and Maria T. Martinez-Garcia. 2014. That-variation in German and Spanish L2 English. Language and Cognition 6: 271-99. [CrossRef] 